\title{
Carotid Duplex Ultrasound Findings in Patients with Coronary Artery Disease (CAD)- A Study in 50 Cases
}

\author{
MS Bari ${ }^{1}$, MS Kabir ${ }^{1}$, MA Ali ${ }^{2}$, SAN Alam², AAS Majumder ${ }^{2}$, \\ AKM Mohibullah' ${ }^{2}$ MN Islam ${ }^{3}$ \\ ${ }^{1}$ Department of Cardiology, Dinajpur Medical College. Dinajpur. ${ }^{2}$ Department of Cardiology, National \\ Institute of Cardiovascular Diseases, ${ }^{3}$ Department of Cardiology, Bangabandhu Sheikh Mujib Medical \\ University, Dhaka.
}

Keywords:

Carotid

atherosclerosis,

Carotid duplex

ultrasound,

Coronary

artery disease.

\begin{abstract}
Background: Patients with angina pectoris or myocardial infarction are more likely to experience stroke. Ischaemic stroke has been found to develop in approximately 2-5\% of patients in the first 1 2 weeks after myocardial infarction

Methods: Fifty patients with coronary artery disease admitted to the National Institute of Cardiovascular Diseases (NICVD), Dhaka, were screened for presence of carotid atherosclerosis by duplex ultrasound study during the period of July 98 to August 98.

Results: Carotid lesion were found in 34 patients (68\%) and normal carotids found in 16 patients (32\%). Age range of patients with and without carotid lesions was $56 \pm 5.39$ yrs and $47 \pm 7.91$ yrs respectively. Out of 34 patients, 30 were male (88.2\%) and 4 were female (11.7\%). 29 patients (85.3\%) were smokers, 22 patients (64.7\%) were hypertensive and 9 patients (26.4\%) were diabetic. Dyslipidaemia was found in 16 patients (47\%) and a history of transient ischaemic attack (TIA) was found in 10 patients (29.4\%). A coexistent CAD on coronary (CAG) was found in 31 patients (91.1\%).

Conclusion: Cortaid duplex ultrasound study findings of atherosclerotic lesions in Carotid arteries are good predictors of $C A D$.
\end{abstract}

(CVJ 2008; 1(1) : 44-47)

\section{Introduction}

Population based studies have identified relations between symptoms and signs of coronary artery disease $(\mathrm{CAD})$ and carotid artery disease. Patients with angina pectoris or myocardial infarction are more likely to experience stroke. ${ }^{1}$ Ischaemic stroke has been found to develop in approximately $2-5 \%$ of patients in the first 1-2 weeks after myocardial infarction. ${ }^{2}$ Signs and symptoms of cerebrovascular disease are also important precursors of cardiac complaints. Patients with transient ischaemic attack, asymptomatic bruit, and stroke die of myocardial infarction more often than of cerebrovascular disease. ${ }^{3}$ Studies have also shown that $30-60 \%$ of symptomatic patients with transient ischaemic attacks, asymptomatic carotid bruits and stroke have positive treadmill tests or angiographic evidence of CAD. Study show that, CAD free controls had less extensive carotid atherosclerosis than CAD cases. This also provides evidence that a measure of the degree of carotid artery atherosclerosis is at least as useful as other known risk factors to screen for CAD. ${ }^{4}$ Observational study show that presence of any atherosclerotic findings in the common carotid artery or carotid bulbs was associated with relative acute myocardial infarction (AMI) hazard of 3 folds and presence of small or large plaques showed a 4 fold risk of AMI compared to men free of these manifestations of carotid artery atherosclerosis at the baseline. ${ }^{5}$ Thus assessment of carotid atherosclerosis can be used as a measure of coronary atherosclerosis. Carotid duplex ultrasound study can reliably detect lesions warranting surgery (carotid end arterectomy) when critical stenosis is more than $80 \%{ }^{6}$. Fukuda and his colleges evaluated patients preoperatively for the presence of carotid stenosis by duplex scanning who was undergoing scheduled CABG. In the critical carotid stenosis groups simultaneous carotid endarterectomy and CABG were performed. They concluded that carotid duplex study is very helpful to evaluate the presence of carotid occlusive disease in CABG candidates. ${ }^{7}$ For patients with severe unilateral or bilateral carotid artery disease and a history of transient ischaemic 
attack or stroke, simultaneous carotid endarterectomy and myocardial revascularization may be undertaken. In experienced hands stroke and mortality rates for combined treatment are less than $5 \% .{ }^{8}$ In most other instances, myocardial revascularization precedes carotid endarterectomy. Which may be done weeks or years later, depending on symptoms. Thus this study was aimed to see the presence of carotid atherosclerosis in patients with $\mathrm{CAD}$ and its relation with severity of CAD. This procedure may be helpful to select subjects of CAD having concomitant carotid atherosclerosis. Management of both pathology may sometime be possible in the same setting.

\section{Materials and Methods:}

Presence and extent of carotid atherosclerosis were evaluated in a total of 50 patients of CAD with the help of duplex ultrasound scanner HDI 3000 ultrasound system of ATL. Ultrasound Inc; Washington, USA. Selected scan head was a linear array having operating frequency range 5.0-10.0 $\mathrm{MHz}$ and Doppler frequency 6.0 $\mathrm{MHz}$. Carotid arteries were evaluated on both sides in usual standard planes at multiple levels e.g. Common carotid artery (CCA)-proximal, mid, distal; Carotid bulb; Internal carotid artery (ICA) - origin of ICA, proximal ICA; External carotid artery (ECA) - origin of ECA, proximal ECA.

The procedure included Doppler imaging, B-mode imaging (both with and without Doppler flow detection) and analysis of Doppler signal by spectrum analysis. B- Mode imaging was done to look for wall irregularities, intimal thickening and presence of plaque. Intimal thickening was considered when its thickness measured $>1 \mathrm{~mm}$. A plaque (Localized areas of intimal thickening incorporating sufficient atheroma to develop plaque) was classified as follow:

1. Soft plaque-characterized by low amplitude intraluminal echoes without any acoustic shadowing.

2. Mixed plaque-characterized by greater reflectivity than soft plaque.

3. Hard plaque-characterized by high degree of reflectance and a persistent acoustic shadowing.

4. Intraplaque haemorrhage- characterized by cystic appearing lesion within or subjacent to a plaque. This lesion was believed to be the precursor of an ulcer.

5. Ulceration-usually associated with hard plaque and found to have an irregular appearance along the wall and base.

6. Occlusion-identified by visualization of echogenic material filling the arterial lumen and absence of Doppler velocity signals. Carotid arterial stenosis was assessed from diameter reduction measured by real time B- scan on a longitudinal plane. The plane that showed the smallest diameter was chosen and the residual diameter was measured using an electronic cursor.

All 50 patients underwent coronary angiography (CAG). Carotid evaluation was done within 2-15 days before or after CAG. Findings of CAG and carotid study were evaluated separately by at least two experienced specialists.

Statistical analysis was done by student's $t$ test and chi square tests. P-value $<0.05$ was considered significant.

\section{Results:}

Out of 50 patients $34(68.0 \%)$ had carotid lesions and normal carotids were found in 16 patients (32\%). Ten patients (20.0\%) had intimal thickening only. Atherosclerotic plaque along with intimal thickening was found in 24 patients (48.0\%).

\section{Table-I}

Carotid B-mode scan profile $(n=50)$

\begin{tabular}{lc}
\hline Variables & No. of patients (\%) \\
\hline Atherosclerotic changes detected & $34(68.0)$ \\
Inimal thickening with plaque & $24(48.0)$ \\
Only inimal thickening & $10(20.0)$ \\
\hline
\end{tabular}

Of the 34 patients with carotid lesions, 30 (88.2\%) patients were male and $4(11.7 \%)$ were female. Mean age of those with carotid lesions was $56 \pm 5.39$ yrs. average BMI of patients was $29.39 \pm 2.17$. A history of TIA was found in 10 patients (29.4\%). History of smoking was present 29 patients $(85.3 \%$, hypertension was found in 22 patients (64.7\%), diabetes mellitus (DM) was present among 9 patients (26.47\%) and dyslipidaemia was present in 16 patients $(47.06 \%)$. Coexistent coronary atherosclerotic findings on CAG was found in 31 patients $(91.1 \%)$ 
Table II

Characteristics of patients with carotid atherosclerosis $(n=34)$

\begin{tabular}{lc}
\hline Parameters & No of patients (\%) \\
\hline H/o TIA & $10(29.4)$ \\
Smoking & $29(85.4)$ \\
Hypertension & $22(64.7)$ \\
DM & $9(26.4)$ \\
Hyperlipidaemia & $16(47.0)$ \\
Coexistent CAD & $31(91.1)$ \\
\hline
\end{tabular}

Among the patients with carotid lesions, most of the lesions were in common carotid artery (CCA) and internal carotid artery (ICA). Bilateral lesions were more common.

\section{Table III}

Distribution of intimal thickening and plaque in different carotid arterial level $(n=50)$

\begin{tabular}{lcccc}
\hline $\begin{array}{l}\text { Artery } \\
\text { CCA }\end{array}$ & \multicolumn{2}{c}{ Intimal thickening } & \multicolumn{2}{c}{ Plaque } \\
& $\begin{array}{c}\text { Unilateral } \\
\text { Bilateral } \\
(\%)\end{array}$ & $\begin{array}{c}\text { Unilateral } \\
(\%)\end{array}$ & $\begin{array}{c}\text { Bilateral } \\
(\%)\end{array}$ \\
\hline CCA & $9(18.0)$ & $21(42.0)$ & $7(14.0)$ & $11(22.0)$ \\
ICA & $4(8.0)$ & $18(36.0)$ & $9(18.0)$ & $10(20.0)$ \\
ECA & $4(8.0)$ & $8(16.0)$ & $3(6.0)$ & $3(6.01)$ \\
\hline
\end{tabular}

Coronary artery disease (CAD) was present is 31 patients (91.1\%) with carotid ateriosclerosis. It was absent in 3 patients $(8.8 \%)$ with carotid lesions. On the other hand, of the 16 patients without carotid lesions, $\mathrm{CAD}$ was present in 9 patients (56.2\%) and absent in 7 patients (43.7\%).

Table-IV

Coexistence of carotid atherosclerosis on duplex study and coronary lesions on $C A G(n=50)$

\begin{tabular}{lccc}
\hline $\begin{array}{l}\text { Carotid } \\
\text { atherosclerosis }\end{array}$ & \multicolumn{2}{c}{ CAD } & P-value \\
\hline Present (n=40) & $31(77.5)$ & $9(22.5)$ & $<0.01$ \\
Absent (n=10) & $3(30.0)$ & $7(70.0)$ & \\
\hline x2=8.25.df=1 & \multicolumn{4}{c}{ CAD } & P-value \\
\hline Carotid & \multicolumn{4}{c}{ Absent (\%) } \\
atherosclerosis & Present (\%) & Absent (\%) \\
\hline Present (n=34) & $31(91.18)$ & $3(8.82)$ & $<0.01$ \\
Absent (n=16) & $9(56.25)$ & $7(43.75)$ & \\
\hline
\end{tabular}

\section{Discussion:}

The development of high-resolution ultrasonography of superficial large arteries has enabled the noninvasive assessment of the severity of atherosclerosis in man. Ultrasonography enables the measurement of wall thickness of superficial arteries whereas; in angiography only lumen diameter can be assessed. Intima-media thickness of the common carotid artery on ultrasonography has been recommended as a useful parameter to assess the presence of coronary artery disease in a publication of the American Heart Association. ${ }^{9}$ Duplex ultrasound findings of carotid arteries showing elevated plaque score, increased number of plaques and degree of carotid stenosis were associated with higher risk of prevalent and/or incident coronary atherosclerosis, ${ }^{4,10}$ myocardial infarction, ${ }^{11}$ or stroke. ${ }^{12}$

Carotid duplex ultrasound study is commonly accepted as a noninvasive, safe, inexpensive and reliable method to assess the atherosclerotic changes of large arteries located close to the skin such as carotid artery. In our study, detectable carotid arterial atherosclerotic changes were present is $88.2 \%$ of men and $11.7 \%$ of women. In the cardiovascular heath study, ${ }^{13}$ detectable carotid stenosis was present in $75 \%$ of men and $62 \%$ of women. Carotid atherosclerosis (i.e.-intimal thickening with or without plaque on duplex scan) was present in 34 (68.0\%) cases in this study which is almost similar to that observed by Khoury et $\mathrm{al}^{12}$ and Megien et. ${ }^{14}$ Out of 34 patients with carotid lesion, $70.67 \%$ had intimal thickening with plaque and $29.4 \%$ had intimal thickening only. Atherosclerotic changes were present more in distal common carotid and origin of internal carotid artery and distribution was mostly bilateral. It was similar to the findings of Howard et al. ${ }^{16}$ Presence of carotid atherosclerosis among $30 \%$ of patients without CAD are comparable to that observed by khoury et $\mathrm{al}^{12}$ and Megnien et $\mathrm{al}^{13}$ who found the same as $47 \%$ and $40 \%$ respectively. Among patients with CAD duplex study revealed presence of carotid atherosclerosis in $77.5 \%$ of the study population which is comparable to that described by Khoury et $\mathrm{al}^{12}$ and Megnien et $\mathrm{al}^{14}$ Multivessel CAD was more strongly associated with carotid atherosclerosis than single vessel disease. A strong correlation between the extend of CAD and progression of carotid atherosclerosis was also found by Tanaka et al. ${ }^{17}$ 
A strong association between coronary status with mean intima-media thickness (IMT) at each of three carotid segments was found by Crouse et al. ${ }^{10}$ Thus carotid duplex ultrasound findings of the present study correlate well with the previous similar studies done abroad although no comparable study has been done in our country.

Limitation of the study to be considered is that, this study was done on a selected group of patients, comprising small numbers in one hospital only.

\section{Conclusion}

Cortaid duplex ultrasound study findings of atherosclerotic lesions in Carotid arteries are good predictors of CAD. It identifies individuals most likely to have coronary atherosclerosis. The procedure is non-invasive, safe and easily accessible for interrogation. Early atherosclerotic changes detected by duplex study may be successfully prevented from further atherosclerotic occlusive lesions by measures like dietary advice, physical activity and lipid lowering therapy.

\section{Reference:}

1. Kannel WB, Wolf PA, Vetter J. Manifestations of coronary disease predisposing to stroke: The Framingham study. JAMA. 1983; 25: 2942-2946.

2. Thompson PL, Robinson JS. Stroke after acute myocardial infarction : Relation to infarct size $B M J$. 1978; 2: 457-462.

3. Chambers BR, Norris. JW. Outcome in patients with a symptomatic neck bruit. N Eng J Med. 1986; 315: 860$865 \mathrm{~S}$.

4. Craven TE, RYu JE, Esplanade MA et al. Evaluation of the associations between carotid artery arteriosclerosis and coronary artery stenosis; A case control study. Circulation. 1990; 82: 1230-1242.

5. Tuomilento J. Arstila M, Kaarsalo E. et al. Acute myocardial infarction (AMI) in Finland: Baseline data form the FINMONICA. AMI register in 1983-1985. Eur Heart J. 1992; 13: 577-587.

6. Chen JC. Salvian AJ. Taylor DC. et. al. Can Duplex ultrasonegraphy select appropriate patients for carotid endartarectomy? Eur J Vasc End vasc surg. 1997; 14: 451-456.
7. Fukida I, Ohuchi H, Sato M, et al. Carotid screening with Duplex scanning before coronary artery bypass; Nippon kyobu Geka Gakkai Zasshi [abstract] 1996; 44: 478-83.

8. Loop FD, Muckrcke DD. Surgical treatment of atherosclerotic coronary heart disease. In: Alexander RN. Schlant RC, Foster V. Eds. Hurst's The Heart: Peripheral Vascular Disease. $9^{\text {th }}$ ed. New York, MC Graw-Hill inc, 1998; 1 : 1473-1487.

9. Smiath SC, Greenland P, Grundy SM. Prevention conference V. Beyond secondary prevntion : Identifying the high-risk patient for primary prevention. Executive summary. Circulation. 2000; 101: 111-6.

10. Crouse JR, Harpold GLL, Kahl FR, et al. Evaluation of a scoring system for extracranial carotid atherosclerosis extent with B-mode ultrasound. Stroke. 1986; 17: 270275.

11. Held C, Hjemdahl P, Eriksson SV, et at. Prognostic implication of intima media thickness and plaques in the carotid and femoral arteries in patients with stable angina pectoris. Eur Heart. J. 2001; 22: 62-72.

12. Khoury Z, Schwartz R, GoHiebs S, et al. Relation of coronary artery disease to atherosclerotic disease in aorta, carotid and femoral arteries evaluated by ultrasound. Am J Cardiol. 1997; 80: 1429-1433.

13. O'Leay DH, Polak JF, Manotha TA, et at. Cardiovascular health study collaborative research group: Carotid artery intima and media thickness as a risk factor for myocardial infraction and stroke in older adults. $N$ Eng J Med. 1999: 340: 14-22.

14. Megnien JL, Sen V, Jeannin S et al. Coronary Calcification and its relation to extracoronary atherosclerosis in asymptomatic hypercholesterolalmic men. Circulation. 1992; 85: 1977-1807.

15. Salonen R, Salonen JT. Progression of carotid atherosclerosis and its determinants: a population based ultrasonography study. Atherosclerosis. 1990; 81: 3340.

16. Howard G, Sharrett AR, Heiss G, et al. for the ARIC Investigators. Carotid artery intimal-medial thickness distribution in general population as evaluated by Bmode ultrasound. Stroke. 1993; 24: 1297-1304.

17. Tanaka H, Nishino M, Ishida M, et at. Progression of carotid atherosclerosis in Japanese patients with caronary artery disease. Stroke. 1992; 23: 946-951. 